\title{
A UTILIZAÇÃO DO LÚDICO COMO ESTRTÉGIA DE APRENDIZAGEM DOS CONCEITOS DE CADEIA ALIMENTAR
}

\author{
Caroline Tavares Firmino ${ }^{1}$ \\ Fernanda Vargas Valadares ${ }^{2}$ \\ Juliana Pacheco Ventura ${ }^{3}$ \\ Gizely Azevedo Costa ${ }^{4}$ \\ Adriana Barra Tulli ${ }^{5}$ \\ Silvia Katia de Souza ${ }^{6}$ \\ Monique Moreira Moulin ${ }^{7}$
}

Resumo: O sexto ano do ensino fundamental têm como parte integrante do plano de ensino da disciplina de Ciências os conteúdos de Ecologia, o qual inclui o estudo das cadeias e teias alimentares. Objetivou-se avaliar a contribuição de uma proposta lúdica na aprendizagem dos conceitos de cadeia alimentar em uma turma do sexto ano do ensino fundamental. Adotou-se como recurso metodológico a utilização de um jogo didático, o qual possui quinze cartas, cada uma com a figura de um ser vivo. Os alunos deveriam utilizar todas as cartas para montar três cadeias alimentares distintas, devendo identificar os níveis tróficos de cada um dos seres representados. Ao término da aula foi aplicado um questionário como forma de avaliar a contribuição do jogo na aprendizagem dos alunos. Observou-se que a maior parte da turma compreendeu de forma significativa os conceitos relacionados às cadeias alimentares, demonstrando assim, a eficiência do jogo como facilitador do processo de ensino aprendizagem.

Palavras-chave: Cadeia alimentar; Ecologia; Ensino; Lúdico.

\footnotetext{
${ }^{1}$ Bacharelado em Ciências Biológicas/Instituto Federal do Espírito Santo - Campus de Alegre, Alegre, ES, Brasil. E-mail: tavares.carolini@gmail.com.

2 Bacharelado em Ciências Biológicas/Instituto Federal do Espírito Santo - Campus de Alegre, Alegre, ES, Brasil. E-mail: fernanda_valladares@hotmail.com.

${ }^{3}$ Licenciatura em Ciências Biológicas/Instituto Federal do Espírito Santo - Campus de Alegre, Alegre, ES, Brasil. E-mail: ju7ventura@hotmail.com.

${ }^{4}$ Bacharelado em Ciências Biológicas/Instituto Federal do Espírito Santo - Campus de Alegre, Alegre, ES, Brasil. E-mail: gizelyac.11@hotmail.com.

5 Licenciada em Ciências Biológicas/Instituto Federal do Espírito Santo - Campus de Alegre, Alegre, ES, Brasil. E-mail: adrianatulli2009@hotmail.com.

6 Licenciada em Ciências Biológicas/Instituto Federal do Espírito Santo - Campus de Alegre, Alegre, ES, Brasil. E-mail: silviasouza747@gmail.com.

7 Professora Doutora/Instituto Federal do Espírito Santo - Campus de Alegre, Alegre, ES, Brasil. E-mail: mmmoulin@ifes.edu.br.
} 